\title{
CONTRACT RESEARCH ORGANIZATION AND ITS GROWTH CRITERIA
}

\author{
${ }^{1}$ Arora Neha *, ${ }^{1}$ Arora Nageen, ${ }^{2}$ Khattar Himanshi, ${ }^{1}$ Kaul parinita, ${ }^{3}$ Garg Tarun \\ ${ }^{1}$ Department of Quality Assurance, I.S.F. College of Pharmacy, Moga, Punjab. \\ ${ }^{2}$ Department of Pharmaceutics, I.S.F. College of Pharmacy, Moga, Punjab. \\ ${ }^{3}$ Department of Pharmaceutics, Seth G.L.Bihani S.D. College of Tech. Edu., Sriganganagar.
}

\section{INTRODUCTION}

A Contract Research Organization (CRO) is a service organization which provides support to the pharmaceutical industry and offers various" pharmaceutical research that is essential for conducting clinical trials in the present boom when various complications are involved in the drug discovery process. India occupie very small place in global market as clinical trial industry. But india taking step for growth of various clinical trial organization for conducting of many clinical trials . Various companies are involved in his type of development many examples are thee like Lupin, Quintil, Cipla, Zydus Cadeila and they are also conduct these type of trails with the collaboration of many multinational companies and these Indian companies are making space in foreign .and these companies makes a protocol before conductind a clinical trial that is very typical and handeled by many highly qualified personnal . According to ICH-GCP Contract Research organization define as "A organization contracted by the sponsor to perform one or more of a sponsor's trial-related duties and functions.

\section{NEED OF CLINICAL RESEARCH ORGANIZATION}

During Drug development preclinical and clinical study is performed.

1. Priclinical Study: new molecular entity are tested in test tube and in laboratory animal for assessment of safty and efficacy. It takes 1 to 3 yrs.than moves into human subjects during clinical studies.

\section{Clinical study: It has three phases:}

Phase I: Phase I involves testing for safety in approximately 20 to 100 healthy volunteers.

Phase II: In Phase II, a pool of 100 to 500 volunteers suffering from the specific disease target is tested over a period of a year or longer.

Phase III: Phase III, several thousand people are tested to verify efficacy and long-term safety on a larger scale. Most CROs specialize in either early-stage (preclinical and Phase I trails) or late-stage development (Phase II-III trials)

During this process drugmakers spend billions of dollars per year attempting to discover and sometime compounds failing to reach the consumer. drug companies out- source development work for a variety of reasons, such as temporary or permanent lack of capacity or infrastructure and to focus on core competencies ${ }^{1,2}$.

\section{CONTRACT MANUFACTURING}

It includes:

- Manufacturing of outsourcing-supply of active pharmaceutical ingredients (APIs)

- Development outsourcing-conducting preclinical and clinical trials

for pharmaceutical industry contract manufacturing and research services (CRAMS) totaled revenue 100 billion in 2004 and will grow at an average annual rate of 10.8 percent to reach $\$ 168$ billion by $2009^{3,4}$.

\section{EVOLUTION OF CONTRACT RESEARCH ORGANIZATION}

Prior to the contract research organization, academic institutions and laboratories handled drug development work. In 1962, regulatory control on the development process increased when Congress passed the Kefauver-Harris amendments, according to these amendments it is essential for drug manufacturers to prove efficacy before marketing a new product. The new law took place to ensure greater safety. Due to greater workload, drug companies began to outsource additional studies that couldn't be handled internally. Private firms grow up to help pharmaceutical companies for manage these new challenges, which included more complex clinical trial work to gather data for submis-sion to the Food and Drug Administration. Development outsourcing in this scenario continued through the 1980s, with's major players in outsourced clinical trial management starting operations, including Parexel International PRXL) in 1983 and Pharmaceutical Product Development PPDI in 1985. According to the United States Government Accountability Office, annual inflation-adjusted R\&D expenses increased from nearly $\$ 16$ billion to nearly $\$ 40$ billion from 1993 to 2004, an increase of $147 \%$. While the number of new drug applications for new molecular entities increased only by $7 \%$.. so pharmaceutical firms gave their noncritical studies to CROs and were able to lower their burden and lower their development costs, as CROs paid lower salaries than in-house 
pharma departments. CROs also gave pharma companies the opportunity to turn a portion of fixed development costs into variable costs by shifting studies offsite.

With heightened demand from drug companies ${ }^{4,5,7}$.

\section{CONTRACT RESEARCH ORGANIZATIONS (CROS) IN INDIA}

In India 5\% of global clinical trials are being conducted by 2012. The global CRO industry valued \$18 bn in 2008 showed an increase of $14 \%$ over 2007. The CRO market will grow at an annual rate of $14 \%$ between 2009 and 13 and it will reach reach upto $\$ 35$ bn by 2013.some examples of top multinational pharmaceuticals companies which has led contract research like Novar-tis, Eli Lilly, Pfizer, and GlaxoSmithKline, Aventis etc. To collaboration with Indian Drug Companies like Nicholas Piramal India Ltd., Advinus Thera- peutics, Ranbaxy laboratories, Torrent Pharma, Dr. Reddy's Laboratories, and Cipla etc. ${ }^{6,7}$.

\section{Growth factor of $\mathrm{CRO}^{1,4,5,6}$}

Integration pharma and biotech, Rising $\mathrm{R}$ and $\mathrm{d}$ cost, Demand for global trials, Shift towards strategic outsourcing, Commoditization of services, stringent regulatory environment, pressure to improve clinical pipeline, need of quality auditing, Need of pharmacovigilanc drug discovery.

\section{MARKET STRUCTURE OF CROS}

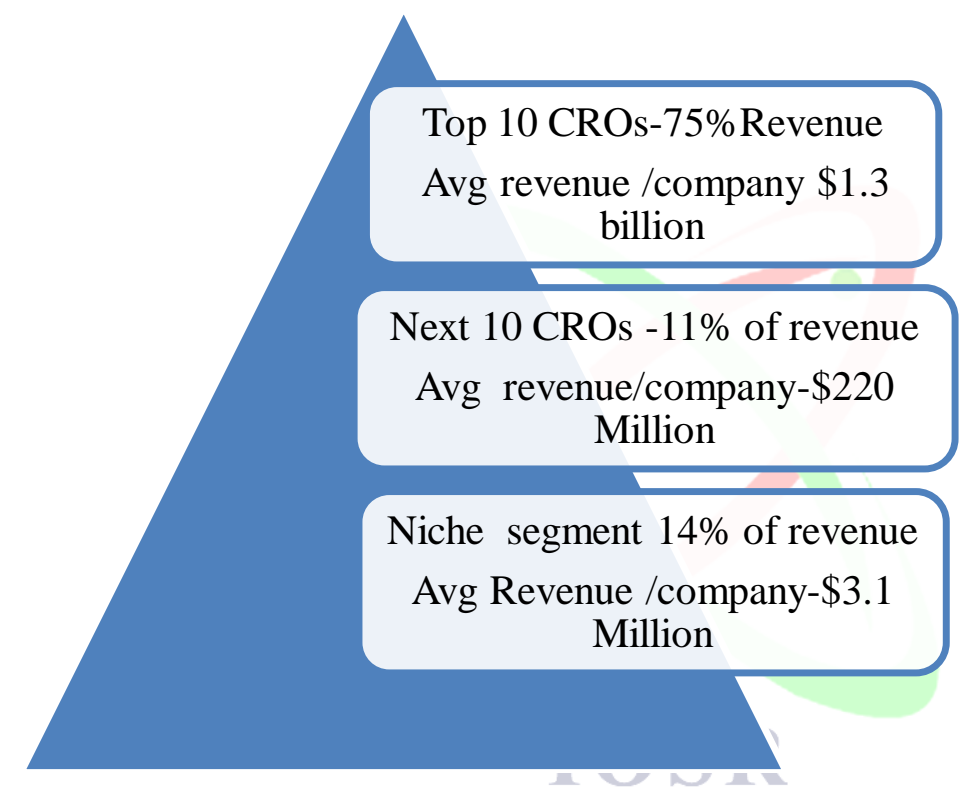

\section{CONCLUSION}

India have lack of funds, and inadequately trained personnel, the drug approval process in India is extremely slow when compared to countries like U.K..if we have easily available qualified personnal, financial status, collaboration with foreign countries, amendments in Indian laws will help to grow the CROs.

\section{REFERENCES}

[1] R. Sehgal, Outsourcing clinical trials to India - opportunities and challenges, The Pharmacol Rev, 2009,29-30.

[2] C. Adithan, National pharmacovigilance programme, Indian J Pharmacol, 37(6), 2005,347.

[3] Y. Murti, P. Verma, D. Pathak, Awareness of the risk factors in volunteers of clinical trials, The Pharma Review, 2009, 68.

[4] S. Nundy, C.M. Gulhati, A new colonialism? Conducting clinical trials in India, N Eng J Med, 352(16), 2005,1633-6.

[5] The Indian pharmaceutical industry,john moris,kpeg pharmaceutical practice.

[6] I. Zinnikus, C. Hahn, K. Fischer, A model-driven, agent-based approach for the integration of services into a collaborative business process.

[7] L. Padgham, D. C. Parkes, J. P. Mller, S. Parsons (Eds.), AAMAS (1), IFAAMAS, 2008, 241-248.

[8] J. Zieba, B. Kryza, R. Slota, L. Dutka, J. Kitowski, Ontology Alignment for Contract Based Virtual Organizations Negotiation and Operation,in: PPAM, 4967, 2007, 835-842

[9] J. Gangilt, S. Gautam, T. Kumar, R. Rajesh, G. Thunga, S. Pandey, Clinical research opportunities in India: beyond the future, The Pharmacol Buzz, 2009,6-7. 